UDC 341.942 .3

LBC 67.93

\title{
THE ISSUES OF LAW APPLICABLE IN THE FIELD OF DELICTUAL CROSS-BORDER RELATIONS
}

\author{
Agnessa O. Inshakova \\ Volgograd State University, Volgograd, Russian Federation \\ Yuliya A. Tymchuk \\ Volgograd State University, Volgograd, Russian Federation
}

Introduction. The article reveals the objective factors of the development of temporal reality, influencing the emergence of various relationships with non-contractual legal nature, the so-called quasi contractual and delictual relations, as well as determines the relevance of research and development in the relevant field of legal regulation relating to private international law.

Purpose. We study the range of possible conflicts of law issues under moves to collision of tort regulation of relations in various foreign governmental legislations, including European law. We also carry out the analysis of the common classical collisional bindings in the area of tort liabilities. It is noted that the current approach lies in the gradual abandonment of territorial binding to any specific element of the relationship. The authors say about the validity of the rapid development of flexible legal regulation of relations arising out of foreign element, associating this trend with the development of the principle of flexibility as fundamental principles and modern trends of development of modern private international law.

The authors examine the background and novellas by the national legislator of the reform of section VI of part three of the civil code.

A brief legal description of the updated provisions of the civil code of the Russian Federation is dedicated to the applicable law in the field of tort obligation.

We commented the possibility of concluding agreements on the law of the subject applications provided by law to the parties. The conclusion about compliance of this rule to the development of the principle of auto-nomia the will of the parties in international private law and foreign legislatortion approaches.

Conclusion. We identified and commented on the advantages and disadvantages of new collision norms in the updated Civil Code, previously unknown to national law, and examined judicial practice of their application. The general conclusion is represented by assessing the modern legal approaches to the applicable law in the field of tort obligations, complicated by a foreign element, which allowed to identify and to list a number of trends in the development of their conflict-of-laws regulation.

Key words: non-contractual obligations, the obligation of the injury, the obligation owing to unjust enrichment, the obligation due to unfair competition, conflict management, connecting factors, the conflict of laws principles, the principle of flexible conflict management, you-Bor applicable law.

УДК 341.942 .3

ББК 67.93

ВОПРОСЫ ПРИМЕНИМОГО ПРАВА В СФЕРЕ ДЕЛИКТНЫХ ОТНОШЕНИЙ С ИНОСТРАННЫМ ЭЛЕМЕНТОМ

\author{
Агнесса Олеговна Иншакова
}

Волгоградский государственный университет, г. Волгоград, Российская Федерация

Юлия Александровна Тымчук

Волгоградский государственный университет, г. Волгоград, Российская Федерация 
Введение: в статье определяются объективные факторы развития современной действительности, влияющие на возникновение разнообразных отношений, имеющих внедоговорную правовую природу, так называемых квазидоговорных и деликтных отношений, а также обусловливающие актуальность научно-исследовательских разработок в соответствующей сфере правового регулирования, относящейся к области международного частного права. Цель: изучить круг возможных коллизионных вопросов и обусловленных ими и социально-экономической действительностью правовых подходов к коллизионному регулированию деликтных отношений в различных зарубежных законодательствах, в том числе в общеевропейском праве. Методы: основу методологического арсенала статьи составляют использованные в ней методы научного познания, анализа и сравнительно-правовой. Результаты: проводится анализ распространенных классических коллизионных привязок в сфере деликтных обязательств. Отмечается, что современный подход заключается в постепенном отказе от территориальной привязки какого-либо конкретного одного элемента правоотношения. Авторы говорят об обоснованности быстрого развития гибкого правового регулирования отношений, возникающих из причинения вреда, осложненных иностранным элементом, связывая эту тенденцию с развитием принципа гибкости как основополагающего начала и современной тенденцией развития современного международного частного права. Изучаются предпосылки и новеллы проведенной национальным законодателем реформы раздела VI части третьей ГК РФ, в ходе которой были вполне справедливо учтены современные зарубежные законодательные подходы правового регулирования деликтных отношений. Дается краткая правовая характеристика обновленных положений ГК РФ, посвященных применимому праву в сфере деликтных обязательств. Комментируется законодательно предоставленная сторонам обязательства из причинения вреда возможность заключения соглашения о праве, подлежащем применению. Делается вывод о соответствии данного правила развитию принципа автономии воли сторон в международном частном праве и иностранным законодательным подходам. Выводы: выявляются и оцениваются преимущества и недостатки новых коллизионных норм в обновленном ГК РФ, ранее не известных национальному законодательству, исследуется судебная практика их применения. Обобщающим выводом выступает оценка современных правовых подходов к применимому праву в области деликтных обязательств, осложненных иностранным элементом, которые позволили выявить и перечислить ряд тенденций развития их коллизионного регулирования.

Ключевые слова: внедоговорные обязательства, обязательство из причинения вреда, обязательство вследствие неосновательного обогащения, обязательство вследствие недобросовестной конкуренции, коллизионное регулирование, коллизионные привязки, коллизионные принципы, принцип гибкого коллизионного регулирования, выбор применимого права.

\section{Введение}

В условиях мировой интеграции и, как следствие, ускорения темпов миграции населения, усложнения экономических отношений, дальнейшего научно-технического прогресса и интенсификации инновационной деятельности, доведенной до стадии сложного производства готового продукта, все чаще возникают разнообразные отношения, имеющие внедоговорную правовую природу. Речь идет о так называемых квазидоговорных и деликтных отношениях, которые благодаря вышеуказанным объективным факторам развития современной действительности все чаще «усложняются» иностранным элементом и приобретают характер международных [7].

При рассмотрении деликтных споров коллизионная проблема, состоящая в определении применимого права, может возникнуть при решении различного рода вопросов. По-разному, например, разрешаются вопросы определения оснований возмещения вреда; квалификации деяния как деликта; установления деликтоспособности субъектов; бремени доказывания вины делинквента; ответственности без вины; значения вины потерпевшего; определения размера и порядка возмещения ущерба.

\section{Традиционные и новейшие мировые тенденции \\ коллизионного регулирования деликтных отношений}

Традиционно в законодательстве разных стран закреплялась основная, порой единственная, коллизионная привязка - право государства места причинения вреда. В условиях интернационализации социохозяйственных отношений появляются новые виды правонарушений, что приводит к трудностям правильной локализации правоотношения при помощи «жестких» коллизионных привязок типа места совершения правонарушения. 
Новейшие тенденции мирового масштаба в правовом регулировании деликтных отношений демонстрируют все большее использование в данной области альтернативных коллизионных норм, в силу которых по выбору потерпевшего деликтные обязательства подчиняются либо праву места возникновения вреда, либо закону места совершения правонарушения.

Законодательство и практика многих стран комбинируют применение закона места совершения правонарушения с иными коллизионными правилами в том или ином сочетании. Это могут быть привязки к закону суда, закону гражданства или домицилия сторон, флагу судна, месту регистрации транспортного средства и т. д. Чаще всего используется привязка деликтного отношения к праву страны, с которой это отношение имеет наиболее тесную связь, с которой связаны стороны деликтных отношений (общее гражданство, общее постоянное место жительства и др.).

Анализ распространенных классических коллизионных привязок объясняет их цель желание прикрепить правоотношение к конкретному месту, на котором находится объект или субъект этих правоотношений, либо имеет место юридический факт, приведший к возникновению, изменению или прекращению правоотношения.

Современный подход заключается в постепенном отказе от территориальной привязки какого-либо конкретного одного элемента правоотношения, например, места нахождения стороны, имущества, совершения деликта, в связи с тем, что эти обстоятельства могут оказаться несущественными и неопределяющими для нахождения правового пространства, к которому привязано все правоотношение в целом.

Следует отметить быстрое развитие гибкого правового регулирования отношений, возникающих из причинения вреда, осложненных иностранным элементом. Так называемый принцип гибкости, как основополагающая тенденция развития современного международного частного права, в полной мере нашел свое отражение и в сфере коллизионного регулирования деликтных отношений, осложненных иностранным элементом [6].

\section{Трансформация} коллизионных принципов

\section{регулирования деликтных отношений вследствие реформы ГК РФ}

В третьей части ГК РФ рассматриваемым отношениям посвящен ряд статей. Это ст. 1219-1221, регулирующие обязательства из причинения вреда, включая ответственность за вред, причиненный товаром, работой или услугой, а также ст. 1222 и 1223, устанавливающие коллизионно-правовое регулирование обязательств вследствие недобросовестной конкуренции и неосновательного обогащения.

В 2013 г. раздел VI ч. 3 ГК РФ подвергся значительному реформированию, в ходе которого были вполне справедливо учтены современные зарубежные законодательные подходы правового регулирования деликтных отношений. В частности, за основу были взяты многие положения Регламента (ЕС) Европейского парламента и Совета от 11 июля 2007 г. «О праве, подлежащем применению к внедоговорным обязательствам» (Рим II) [17]. Так, например, основным коллизионным принципом по-прежнему является закон страны места причинения вреда (закон страны, где имело место действие или иное обстоятельство, послужившее основанием для требования о возмещении вреда (п. 1 ст. 1219 ГК РФ), однако он не исключает применения специальных коллизионных норм при соблюдении определенных условий.

Дадим краткую правовую характеристику обновленных положений ГК РФ, посвященных применимому праву в сфере деликтных обязательств.

Так, в ст. 1219 ГК РФ был внесен ряд изменений относительно применимого права к обязательствам из причинения вреда, в результате которых сегодня существует несколько привязок [20].

1. По общему правилу к обязательствам, возникающим вследствие причинения вреда, применяется право страны, где имело место действие или иное обстоятельство, послужившие основанием для требования о возмещении вреда. В случае, если действие или иное обстоятельство, причинившее вред, было совершено в одной стране, а вред наступил в другой, то может быть применено 
право страны, в которой проявились такие негативные последствия. Привязка может изменяться, если причинитель вреда предвидел или должен был предвидеть наступление вреда в этой стране.

Анализ п. 1 ст. 1219 ГК РФ позволяет прийти к выводу о возможности применения двух коллизионных привязок. Наличие подобной альтернативы позволяет, на наш взгляд, наиболее полно учитывать фактические обстоятельства каждого конкретного дела.

Как правило, применение при разрешении спора коллизионной привязки «закон места причинения деликта» у судов не вызывает трудностей. Например, в случае причинения вреда иностранным юридическим лицом гражданину РФ в результате ДТП на территории России суд при рассмотрении дела о взыскании ущерба применяет законодательство Российской Федерации [18].

Одним из условий использования коллизионной привязки «закон места причинения вреда» выступает предвидение или обязанность предвидения причинителем вреда наступления его в этой стране. Однако указание в статье на возможность применения права страны, в которой проявились такие негативные последствия, свидетельствует о том, что суд не обязан применять право страны, где наступил вред, несмотря на соблюдение условия о предвидении наступления вреда в этой стране.

Возникает вопрос: на ком лежит бремя доказывания необходимости применения права страны, где наступил вред, а также возможности или обязанности предвидения наступления вреда в другой стране?

По данному вопросу существуют две противоположные позиции. Согласно первой бремя доказывания возможности предвидеть наступление вреда возлагается на истца, а не на делинквента [16, с. 164]. Другие исследователи считают, что предвидение причинителем вреда наступления вредоносного результата в другой стране должно презюмироваться. Причем п. 1 ст. 1219 ГК РФ позволяет толковать его исходя из интересов «слабой» стороны, то есть потерпевшего, а ответчик вправе возражать против применения права другой страны и доказывать обратное $[9$, c. 72$]$.
Помимо указанного немаловажным является вопрос о том, по чьей инициативе может быть признано применимым право места наступления вреда. Специалисты указывают на то, что ставить вопрос о применении права страны места наступления вреда может как потерпевший, так и в его интересах суд по своей инициативе [4, с. 209]. На наш взгляд, наиболее логичным решением является самостоятельный выбор потерпевшим наиболее выгодного для него права, подлежащего применению при разрешении спора.

Доказательствами, на которые можно ссылаться в обоснование своих требований о необходимости применения права страны места наступления вреда, являются, например, сведения о наличии у делинквента достоверной информации о маршруте следования, о погодных условиях, которые могли затруднить доставку груза и т. д.

Так, например, истец обратился в суд с иском о взыскании ущерба и процентов по ст. 413 КТМ РФ. Внедоговорной ущерб возник в результате следующих обстоятельств: танкер (флаг Россия) с грузом мазута переломился пополам, попав в шторм, что привело к его разливу и, как следствие, загрязнению акватории и прилегающей береговой полосы. Однако стихийное явление не носило исключительного характера, кроме того, капитан судна заблаговременно имел неблагоприятный прогноз погоды и, полагаясь на свой опыт плавания в данном районе, посчитал, что изменение погоды не приведет к последствиям, при которых произойдет разлом судна. Таким образом, капитаном не были предприняты все необходимые меры во избежание крушения судна. Из этого следует, что основания для освобождения собственника судна от ответственности за ущерб от загрязнения отсутствуют (п. 2 ст. 3 Международной конвенции о гражданской ответственности за ущерб от загрязнения нефтью 1992 г., ст. 317 КТМ РФ). Суд, руководствуясь нормами ст. 1219 ГК РФ, посчитал, что поскольку вопросы исчисления процентов Международной конвенцией о гражданской ответственности за ущерб от загрязнения нефтью 1992 г. не затронуты, то они должны быть разрешены по нормам национального права, определяемого на основании положений коллизионного регулирования, содержащихся в указан- 
ной статье, с учетом принципа закона места совершения деликта [13].

В другом деле, приняв во внимание то обстоятельство, что существующими международными договорами Российской Федерации и правом иностранного государства, подлежащим применению вследствие причинения вреда при осуществлении правосудия, право не было определено, суд пришел к выводу, что в спорном случае в силу п. 1 ст. 1186, п. 1 ст. 1219 ГК РФ должно было применяться законодательство Российской Федерации, то есть страны, на территории которой гражданину иностранного государства был причинен вред [11].

2. Если стороны обязательства, возникающего вследствие причинения вреда, имеют место жительства или основное место деятельности в одной и той же стране, применяется право этой страны. Если стороны данного обязательства имеют место жительства или основное место деятельности в разных странах, но являются гражданами или юридическими лицами одной и той же страны, применяется право этой страны.

Ранее выбор применимого права ставился в первую очередь в зависимость от национальной принадлежности сторон. Исключением являются лишь случаи причинения вреда, который вытекает из существующего договора.

Например, в результате произошедшего на территории Финляндии ДТП, участниками которого были водители - граждане РФ, одному из автомобилей были причинены механические повреждения. Ответственность лица, виновного в ДТП, была застрахована в соответствии с требованиями международной системы страхования гражданской ответственности владельцев транспортных средств. В адрес виновного в ДТП поступила претензия от пострадавшего с требованием перечислить сумму страхового возмещения, которая была им перечислена не в полном объеме. В результате пострадавший обратился с соответствующим иском в суд. Поскольку ДТП произошло на территории Республики Финляндии, судом первой инстанции были применены нормы иностранного права. Однако, анализируя п. 2 ст. 1219 ГК РФ, суд указал, что данная норма устанавливает применение соответствующего права по обязательствам, возникшим из причинения вреда за границей, то есть к внедого- ворным обязательствам. Поэтому положения п. 2 ст. 1219 ГК РФ не применяются в связи с тем, что обязательства ответчика по выплате страхового возмещения вытекают из договора, а не из причинения вреда [15].

Проведенный анализ обновленной редакции п. 2 ст. 1219 ГК РФ позволил выявить два кардинально новых аспекта в законодательном подходе регулирования трансграничных деликтов:

- во-первых, приоритет в отношении права, подлежащего применению, смещен в сторону обстоятельств, связанных с местом жительства или основным местом деятельности причинителя вреда и потерпевшего в одной и той же стране. Подобный подход полностью согласуется с положениями ст. 4 Регламента (ЕС) Европейского парламента и Совета от 11 июля 2007 г. «О праве, подлежащем применению к внедоговорным обязательствам» (Рим II);

- во-вторых, расширена сфера применения статьи; если ранее она применялась только к обязательствам, возникающим вследствие причинения вреда за границей, то есть за пределами России, то сейчас в п. 2 ст. 1219 ГК РФ речь также идет о причинении вреда и в России (например, туристами, находящимися в России и причинившими вред друг другу). Прежнее регулирование предполагало применение права общего гражданства или общего места жительства одной из сторон только при условии, что деликт был совершен за границей. Подобное регулирование фактически стирало основное коллизионное правило и не отвечало мировым стандартам. Обновленная редакция устранила данную проблему.

3. Если из совокупности обстоятельств дела вытекает, что обязательство, возникающее вследствие причинения вреда, тесно связано с договором между потерпевшим и причинителем вреда, заключенным при осуществлении этими сторонами предпринимательской деятельности, применимым к данному обязательству будет право, подлежащее применению к такому договору (п. 3 ст. 1219 ГК РФ).

Анализ данной нормы свидетельствует о том, что:

- во-первых, она является исключением из общего правила, установленного п. 1 ст. 1219 ГК РФ; 
- во-вторых, в ней устанавливается акцессорная коллизионная привязка, которая больше всего актуальна для стран, допускающих конкуренцию деликтных и договорных исков [3, с. 11];

- в-третьих, в ней нашел свое отражение принцип наиболее тесной связи, однако в более ограниченном виде по сравнению с положением п. 3 ст. 4 Регламента (ЕС) Европейского парламента и Совета от 11 июля 2007 г. «О праве, подлежащем применению к внедоговорным обязательствам» (Рим II), согласно которому «если из всех обстоятельств дела вытекает, что причинение вреда имеет явно более тесные связи с другой страной, то применяется право этой другой страны». Явно более тесная связь с другой страной может основываться, в частности, на договорном отношении, ранее сложившемся между сторонами, которое тесно связано с соответствующим причинением вреда.

Полагаем, что подход отечественного законодателя является более верным. Несмотря на расширение судейского усмотрения при оценке всех обстоятельств дела, избранная законодателем позиция позволит судам избежать трудностей и ошибок при установлении тесной связи деликта с другим государством.

4. Стороны обязательства из причинения вреда могут заключить соглашение о праве, подлежащем применению к обязательству из причинения вреда. В случае отсутствия соглашения применяются правила ст. 1219 ГК РФ [2]. Это правило отражает принцип автономии воли сторон и соответствует подходам иностранных государств. При этом стороны могут выбрать право любой страны, а не только права страны суда, как было предусмотрено ранее.

Закрепление указанного правила соответствует общей тенденции развития международного частного права: расширение автономии воли сторон путем урегулирования спорных отношений посредством договоренностей, которые, однако, не должны затрагивать права третьих лиц. Причем предполагается, что заключить соглашение о праве, подлежащем применению к обязательству из причинения вреда, стороны могут только непосредственно после совершения деликта.
Статья 1220 ГК РФ не претерпела изменений в результате реформы и по-прежнему определяет сферу действия права, подлежащего применению к обязательствам, возникающим вследствие причинения вреда. Данная статья устанавливает, какие отношения охватываются правопорядком, выбранным с помощью коллизионной нормы.

\section{Коллизионные принципы регулирования некоторых специальных видов внедоговорных обязательств по ГК РФ}

ГК РФ дополнен новой коллизионной нормой для специального вида внедоговорного обязательства, а именно ст. 1220.1, устанавливающей возможность предъявления требований о возмещении вреда непосредственно страховщику, если это допускается по праву, подлежащему применению к обязательству, возникающему вследствие причинения вреда, или по праву, подлежащему применению к договору страхования. Аналогичное правило, послужившее основой для ст. 1220.1 ГК РФ, закреплено в ст. 18 Регламента (ЕС) Европейского парламента и Совета от 11 июля 2007 г. «О праве, подлежащем применению к внедоговорным обязательствам» (Рим II).

Так, например, в одном из дел суд применил ст. 1220.1 ГК РФ и п. 1 ст. 1219 ГК РФ ввиду того, что спорные правоотношения между сторонами вытекают из требований о возмещении вреда, причиненного вследствие дорожно-транспортного происшествия, которое произошло в городе Севастополе, являющемся на момент рассмотрения гражданского дела по апелляционной жалобе территорией Российской Федерации. Исходя из этого суд пришел к выводу о применении на стадии апелляционного пересмотра дела норм российского законодательства - по праву страны, на территории которой имело место действие, послужившее основанием для требования о возмещении вреда [1].

Из ст. 1221 ГК РФ усматривается, что законодатель предоставляет потерпевшему право выбора применимого права в случаях, когда вред возник в результате недостатков товара, работы или услуги. В этом случае может быть применимо право страны места 
жительства или основного места деятельности продавца (изготовителя или иного причинителя вреда); страны места жительства или основного места деятельности потерпевшего; страны, где была выполнена работа (оказана услуга, приобретен товар).

Вместе с тем право такого выбора ограничено в случае, если причинитель вреда докажет, что он не предвидел и не должен был предвидеть распространение товара в соответствующей стране. В данном случае применимым правом будет только право страны, где имеет место жительства или основное место деятельности продавец товара либо иной причинитель вреда. Это же право (при условии, что из закона, существа обязательства либо совокупности обстоятельств дела не вытекает иное) применяется в случае, если потерпевший не выбрал применимое право.

Кроме того, стороны также могут заключить соглашение о применимом праве.

Одним из недостатков ст. 1221 ГК РФ является нерешенность вопроса о сфере ее применения. Здесь возникает вопрос: данная норма распространяется на случаи по возмещению вреда, причиненного вследствие недостатков товаров, работ или услуг, которые были приобретены (оказаны) исключительно в потребительских целях, или она может быть применена и в ситуациях причинения названного вреда в связи с осуществлением предпринимательской деятельности?

Судебная практика не дает однозначного ответа на данный вопрос $[10 ; 12 ; 14]$.

В литературе существуют три различных подхода. Согласно первому сфера применения рассматриваемой статьи ограничена лишь потребительскими целями [5, с. 228]. Существует и противоположная позиция, отстаивающая возможность применения данной нормы не только к отношениям, в которых присутствует потребительская цель, но и к отношениям, связанным с предпринимательской деятельностью [8, с. 444].

На наш взгляд, наиболее верным является третий подход [19, с. 273]. Так, для ответа на поставленный вопрос необходимо прежде всего исходить из ст. 1187 ГК РФ, устанавливающей, что при определении права, подлежащего применению, толкование юридических понятий необходимо осуществ- лять в соответствии с российским правом. Поэтому, обратившись к ст. 1095 ГК РФ, можно прийти к выводу о том, что сфера применения ст. 1221 ГК РФ ограничена возмещением вреда, причиненного вследствие недостатков товаров, работ или услуг, которые были приобретены (оказаны) исключительно в потребительских целях.

\section{Выводы}

Таким образом, оценивая современные правовые подходы к применимому праву в области деликтных обязательств, осложненных иностранным элементом, можно выявить ряд тенденций развития их коллизионного регулирования:

- во-первых, анализ действующего российского и международного законодательства свидетельствует о существовании сформировавшейся системы генеральных и субсидиарных коллизионных привязок в рассматриваемой сфере;

- во-вторых, в законодательстве прослеживается наделение двусторонним характером некоторых традиционно применяемых односторонних коллизионных норм (дифференциация коллизионных привязок);

- в-третьих, значительно расширилась сфера использования автономии воли сторон при определении и выборе права, подлежащего применению;

- в четвертых, реформа третьей части ГК РФ и внесение соответствующих изменений в нормы, регулирующие рассматриваемый круг отношений, позволяют говорить о наметившейся унификации и гармонизации норм российского и международного права (Регламент (ЕС) Европейского парламента и Совета от 11 июля 2007 г. «О праве, подлежащем применению к внедоговорным обязательствам» (Рим II)).

\section{СПИСОК ЛИТЕРАТУРЫ}

1. Апелляционное определение Апелляционного суда г. Севастополя от 18 нояб. 2014 г. по делу № 33-65/2014. - Доступ из справ.-правовой системы «КонсультантПлюс».

2. Апелляционное определение Верховного суда Республики Крым от 23 дек. 2015 г. № 33-9987/ 
2015. - Доступ из справ.-правовой системы «КонсультантПлюс».

3. Асосков, А. В. Реформа раздела VI «Международное частное право» Гражданского кодекса РФ / А. В. Асосков // Хозяйство и право. - 2014. № 2. - С. 3-28.

4. Гражданский кодекс Российской Федерации. Часть третья. Раздел VI «Международное частное право». Комментарий и постатейные материалы / отв. ред. Н. И. Марышева. - М. : Контракт : Инфра-М, 2004. - 823 с.

5. Дмитриева, Г. К. Комментарий к Гражданскому кодексу Российской Федерации, части третьей, разделу VI «Международное частное право» / Г. К. Дмитриева. - М. : Норма, 2002. - 248 с.

6. Иншакова, А. О. Арбитражное соглашение как договорный способ закрепления принципа гибкости в международном частном праве / А. О. Иншакова, С. Ю. Казаченок // Вестник Волгоградского государственного университета. Серия 5, Юриспруденция. -2013 . - № 1. - С. 66-71.

7. Иншакова, А. О. Международное частное право / А. О. Иншакова. - М. : Юрайт, 2016. - [В печати].

8. Комментарий к Гражданскому кодексу Российской Федерации. В 3 т. Т. 3. Комментарий к Гражданскому кодексу Российской Федерации, части третьей / под ред. Т. Е. Абовой, М. М. Богуславского, А. Г. Светланова. - М. : Юрайт, 2007. - 486 с.

9. Марышева, Н. И. Современные тенденции коллизионного регулирования деликтных обязательств: регламент ЕС 2007 г. «О праве, подлежащем применению к внедоговорным обязательствам» (Рим II) и российское законодательство / Н. И. Марышева // Журнал российского права. - 2016. № 6. - С. 63-73.

10. Определение Верховного суда РФ от 13 апр. 2016 г. № 305-ЭС16-1527 по делу № А40-103277/13 . Доступ из справ.-правовой системы «КонсультантПлюс».

11. Постановление Восемнадцатого арбитражного апелляционного суда от 22 янв. 2014 г. № 18АП11721/2013 по делу № А34-806/2013 // Картотека арбитражных дел. - Электрон. текстовые дан. - Режим доступа: http://kad.arbitr.ru/PdfDocument/ 6218fb3e-bc44-4eb7-8b38-58d977531f4e/A34-8062013_20140122_Postanovlenie \%20apelljacionnoj\% 20instancii.pdf(дата обращения: 10.08.2016). -Загл. с экрана.

12. Постановление Пленума Верховного суда РФ «О рассмотрении судами гражданских дел по спорам о защите прав потребителей» от 28 июня 2012 г. № 17. - Доступ из справ.-правовой системы «КонсультантПлюс».

13. Постановление Тринадцатого арбитражного апелляционного суда от 3 окт. 2012 г. по делу № А56-2435/2008 // Картотека арбитражных дел. -
Электрон. текстовые дан. - Режим доступа: http:// kad.arbitr.ru/PdfDocument/04c96a29-72c8-4db4-9030e 1 e 9244 b0 1 ab/A 56-2435-2008 20121003 Postanovlenie\%20 apelljacionnoj\% $\%$ 20instancii.pdf (дата обращения: 10.08.2016). - Загл. с экрана.

14. Постановление ФАС Дальневосточного округа от 4 марта 2013 г. № Ф03-6439/2012 по делу № A51-2386/2012 // Картотека арбитражных дел. Электрон. текстовые дан. - Режим доступа: http:// kad.arbitr.ru/PdfDocument/deb16a88-6f6f-4aee-8da8abdf0f302a67/A 5 1-2386-2012_20130304 Postanovlenie\%20 kassacionnoj\%20instancii.pdf (дата обращения: 01.08.2016). - Загл. с экрана.

15. Постановление ФАС Северо-Западного округа от 6 сент. 2012 г. по делу № А 56-58037/2011 // Картотека арбитражных дел. - Электрон. текстовые дан. - Режим доступа: http://kad.arbitr.ru/ PdfDocument/f64c2095-6flb-43cf-a526-9307eae51928/ A56-58037-2011_20120906_Postanovlenie\%20 kassacionnoj\%20instancii.pdf (дата обращения: 10.08.2016). - Загл. с экрана.

16. Постатейный комментарий к разделу VI / М. М. Богуславский, Б. М. Гонгало, А. В. Демкина [и др.] ; под ред. П. В. Крашенинникова. - М. : Статут, 2014. -200 c.

17. Регламент «О праве, подлежащем применению к внедоговорным обязательствам» («Рим IІ») от 11 июля 2007 г. № 864/2007 // Право.ru. - Электрон. текстовые дан. - Режим доступа: http://docs.pravo.ru/ document/view/20385629 (дата обращения: 10.08.2016).Загл. с экрана.

18. Решение Арбитражного суда Республики Башкортостан от 26 июня 2014 г. по делу № А07-478/ 2014 // Росправосудие. - Электрон. текстовые дан. Режим доступа: https://rospravosudie.com/court-asrespubliki-bashkortostan-s/judge-zhuravleva-marinaviktorovna-s/act-309339881/ (дата обращения: 12.08.2016). - Загл. с экрана.

19. Сергеев, А. П. Комментарий к Гражданскому кодексу Российской Федерации (постатейный). Часть третья / А. П. Сергеев, Ю. К. Толстой, И. В. Елисеев. - М. : Проспект, 2002. - 304 с.

20. Федеральный закон «О внесении изменений в часть третью Гражданского кодекса Российской Федерации» от 30 сент. 2013 г. № 260-Ф3 // Собрание законодательства РФ. - 2013. - № 40. - Ст. 5030.

\section{REFERENCES}

1. Apellyatsionnoe opredelenie Apellyatsionnogo sudag. Sevastopolya ot 18 noyab. 2014 g. po delu № 33$65 / 2014$ [Appeal decision of the Court of Appeal of Sevastopol of November 18, 2014 on the case no. 33-65/ 2014]. Access from reference legal system "KonsultantPlyus". 
2. Apellyatsionnoe opredelenie Verkhovnogo suda Respubliki Krym ot 23 dek. 2015 g. № 33-9987/ 2015 [Appeal decision of the Supreme Court of the Republic of Crimea of December 23, 2015 no. 33-9987/ 2015]. Access from reference legal system "KonsultantPlyus".

3. Asoskov A.V. Reforma razdela VI «Mezhdunarodnoe chastnoe pravo» Grazhdanskogo kodeksa RF [Reform of Section VI "International Private Law" of the Civil Code of the Russian Federation]. Khozyaystvo i pravo, 2014, no. 2, pp. 3-28.

4. Marysheva N.I., ed. Grazhdanskiy kodeks Rossiyskoy Federatsii. Chast tretya. Razdel VI "Mezhdunarodnoe chastnoe pravo». Kommentariy $i$ postateynye materialy [The Civil Code of the Russian Federation. Part Three. Section VI "International Private Law". Comment and itemized materials]. Moscow, Kontrakt Publ.; Infra-M Publ., 2004. $823 \mathrm{p}$.

5. Dmitrieva G.K. Kommentariy k Grazhdanskomu kodeksu Rossiyskoy Federatsii, chasti tretyey, razdelu VI «Mezhdunarodnoe chastnoe pravo» [Comment to the Civil Code of the Russian Federation, part three, section VI "International Private Law"]. Moscow, Norma Publ., 2002. 248 p.

6. Inshakova A.O., Kazachenok S.Yu. Arbitrazhnoe soglashenie kak dogovornyy sposob zakrepleniya printsipa gibkosti v mezhdunarodnom chastnom prave [The arbitration agreement as a way to secure the contractual principle of flexibility in international private law]. Vestnik Volgogradskogo gosudarstvennogo universiteta. Seriya 5, Yurisprudentsiya [Science Journal of Volgograd State University. Jurisprudence], 2013, no. 1, pp. 66-71.

7. Inshakova A.O. Mezhdunarodnoe chastnoe pravo [International Private Law]. Moscow, Yurayt Publ., 2016. (In print).

8. Abova T.E., Boguslavskiy M.M., Svetlanov A.G., eds. Kommentariy $k$ Grazhdanskomu kodeksu Rossiyskoy Federatsii. V 3 t. T. 3. Kommentariy k Grazhdanskomu kodeksu Rossiyskoy Federatsii, chasti tretyey [Comment to the Civil Code of the Russian Federation. In 3 vols. Vol. 3. Commentary to the Civil Code of the Russian Federation, part three]. Moscow, Yurayt Publ., 2007. 486 p.

9. Marysheva N.I. Sovremennye tendentsii kollizionnogo regulirovaniya deliktnykh obyazatelstv: reglament ES 2007 g. «O prave, podlezhashchem primeneniyu k vnedogovornym obyazatelstvam» (Rim II) i rossiyskoe zakonodatelstvo [Modern trends in conflict regulation of tort liability: the EU Regulation 2007 "On the law applicable to non-contractual obligations" (Rome II) and the Russian legislation]. Zhurnal rossiyskogo prava, 2016, no. 6, pp. 63-73.

10. Opredelenie Verkhovnogo suda RF ot 13 apr. 2016 g. № 305-ES16-1527 po delu № A40-
103277/13 [Determination of the Supreme Court of April 13, 2016 no. 305-ES16-1527 on the case no. A40-103277/13]. Access from reference legal system "KonsultantPlyus"

11. Postanovlenie Vosemnadtsatogo arbitrazhnogo apellyatsionnogo suda ot 22 yanv. 2014 g. № 18AP-11721/ 2013 po delu № A34-806/2013 [Resolution of the Eighteenth Arbitration Court of Appeal of January 22, 2014 no. 18AP-11721/2013 on case no. A34-806/2013]. Kartoteka arbitrazhnykh del [Card File of arbitration cases]. Available at: http://kad.arbitr.ru/PdfDocument/ 6218fb3e-bc44-4eb7-8b38-58d977531f4e/A34-8062013_20140122_Postanovlenie\%20apelljacionnoj \%20instancii.pdf. (accessed August 10, 2016).

12. Postanovlenie Plenuma Verkhovnogo suda $R F$ «O rassmotrenii sudami grazhdanskikh del po sporam o zashchite prav potrebiteley» ot 28 iyunya 2012 g. № 17 [Resolution of the Plenum of the Supreme Court of the Russian Federation "On consideration of civil cases by courts in disputes on protection of consumer rights" of June 28, 2012 no. 17]. Access from reference legal system "KonsultantPlyus".

13. Postanovlenie Trinadtsatogo arbitrazhnogo apellyatsionnogo suda ot 3 okt. 2012 g. po delu № A562435/2008 [Resolution of the Thirteenth Arbitration Court of Appeal of October 3, 2012 on the case no. A56-2435/2008]. Kartoteka arbitrazhnykh del [Card File of arbitration cases]. Available at: http:// kad.arbitr.ru/PdfDocument/04c96a29-72c8-4db4-9030e 1 e 9244 b0 1 ab/A 56-2435-2008 20121003 Postanovlenie $\% 20$ apelljacionnoj\% $\%$ - instancii.pdf (accessed August 10, 2016).

14. Postanovlenie FAS Dalnevostochnogo okruga ot 4 marta 2013 g. № F03-6439/2012 po delu № A51-2386/2012 [Resolution of FAC of Far Eastern District of March 4, 2013 no. F03-6439/2012 on the case no. A51-2386/2012]. Kartoteka arbitrazhnykh del [Card File of arbitration cases]. Available at: http:// kad.arbitr.ru/PdfDocument/deb16a88-6f6f-4aee-8da8abdf0f302a67/A51-2386-2012_20130304 Postanovlenie\%20 kassacionnoj\%20instancii.pdf. (accessed August 1, 2016).

15. Postanovlenie FAS Severo-Zapadnogo okruga ot 6 sent. 2012 g. po delu № A56-58037/2011 [Resolution of FAC of Northwestern District of September 6, 2012 on the case no. A56-58037/2011]. Kartoteka arbitrazhnykh del [Card File of arbitration cases]. Available at: http://kad.arbitr.ru/PdfDocument/ f64c2095-6f1b-43cf-a526-9307eae51928/A56-580372011_20120906_Postanovlenie\%20kassacionnoj\% 20instancii.pdf. (accessed August 10, 2016).

16. Boguslavskiy M.M., Gongalo B.M., Demkina A.V. Postateynyy kommentariy $k$ razdelu VI [Itemized Commentary to Section VI]. Moscow, Statut Publ., 2014. 200 p. 
17. Reglament «O prave, podlezhashchem primeneniyu $\mathrm{k}$ vnedogovornym obyazatelstvam» («Rim II») ot 11 iyulya 2007 g. № 864/2007 [Regulation "On the law applicable to non-contractual obligations" ( "Rome II") of July 11, 2007 no. 864/2007]. Pravo.ru. Available at: http://docs.pravo.ru/document/view/ 20385629. (accessed August 1, 2016).

18. Reshenie Arbitrazhnogo suda Respubliki Bashkortostan ot 26 iyunya 2014 g. po delu № A07478/2014 [The decision of the Arbitration Court of the Republic of Bashkortostan of June 26, 2014 on the case no. A07-478/2014]. Rospravosudie [Russian Justice]. Available at: https://rospravosudie.com/courtas-respubliki-bashkortostan-s/judge-zhuravleva- marina-viktorovna-s/act-309339881/. (accessed August 12, 2016).

19. Sergeev A.P., Tolstoy Yu.K., Eliseev I.V. Kommentariy k Grazhdanskomu kodeksu Rossiyskoy Federatsii (postateynyy). Chast tretya [Commentary to the Civil Code of the Russian Federation (itemized). Part Three]. Moscow, Prospekt Publ., 2002. 304 p.

20. Federalnyy zakon $« \mathrm{O}$ vnesenii izmeneniy v chast tretyu Grazhdanskogo kodeksa Rossiyskoy Federatsii» ot 30 sent. 2013 g. № 260-FZ [Federal Law "On amendments to the third part of the Civil Code of the Russian Federation" of September 30, 2013 no. 260FL]. Sobranie zakonodatelstva $R F, 2013$, no. 40, art. 5030 .

\section{Information About the Authors}

Agnessa O. Inshakova, Doctor of Juridical Sciences, Professor, Head of Department of Civil and International Private Law of Volgograd State University, Base Department of the Southern Scientific Center of the Russian Academy of Sciences, Prosp. Universitetsky, 100, 400062 Volgograd, Russian Federation, ainshakova@list.ru, gimchp@volsu.ru.

Yuliya A. Tymchuk, Master Student, Department of Civil and International Private Law, Volgograd State University, Base Department of the Southern Scientific Center of the Russian Academy of Sciences, Prosp. Universitetsky, 100, 400062 Volgograd, Russian Federation, yuliannatymchuk@yandex.ru, gimchp@volsu.ru.

\section{Информация об авторах}

Агнесса Олеговна Иншакова, доктор юридических наук, профессор, заведующая кафедрой гражданского и международного частного права, Волгоградский государственный университет, базовая кафедра ЮНЦ РАН, просп. Университетский, 100, 400062 г. Волгоград, Российская Федерация, ainshakova@list.ru, gimchp@volsu.ru.

Юлия Александровна Тымчук, магистрант кафедры гражданского и международного частного права, Волгоградский государственный университет, базовая кафедра ЮНЦ РАН, просп. Университетский, 100, 400062 г. Волгоград, Российская Федерация, yuliannatymchuk@yandex.ru, gimchp@volsu.ru. 